

\title{
Sputtered titanium carbide thick film for high areal energy on chip carbon-based micro-supercapacitors
}

Manon Létiche, Kevin Brousse, Arnaud Demortiere, Peihua Huang, Barbara

Daffos, Sébastien Pinaud, Marc Respaud, Bruno Chaudret, Pascal Roussel, Lionel Buchaillot, et al.

\section{To cite this version:}

Manon Létiche, Kevin Brousse, Arnaud Demortiere, Peihua Huang, Barbara Daffos, et al.. Sputtered titanium carbide thick film for high areal energy on chip carbon-based micro-supercapacitors. Advanced Functional Materials, 2017, 27 (20), 10.1002/adfm.201606813 . hal-01582136

\section{HAL Id: hal-01582136 \\ https://hal.science/hal-01582136}

Submitted on 5 Sep 2017

HAL is a multi-disciplinary open access archive for the deposit and dissemination of scientific research documents, whether they are published or not. The documents may come from teaching and research institutions in France or abroad, or from public or private research centers.
L'archive ouverte pluridisciplinaire HAL, est destinée au dépôt et à la diffusion de documents scientifiques de niveau recherche, publiés ou non, émanant des établissements d'enseignement et de recherche français ou étrangers, des laboratoires publics ou privés. 


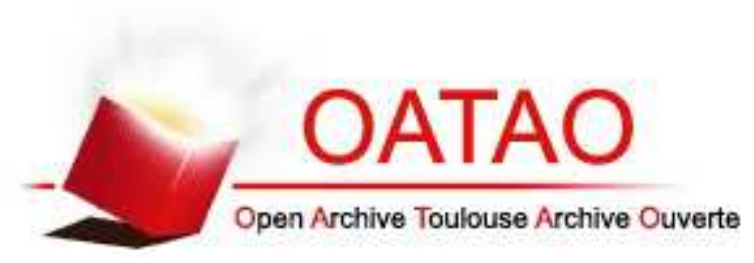

\section{Open Archive TOULOUSE Archive Ouverte (OATAO)}

OATAO is an open access repository that collects the work of Toulouse researchers and makes it freely available over the web where possible.

This is an author-deposited version published in: http://oatao.univ-toulouse.fr/ Eprints ID: 18012

To link to this article: DOI: $10.1002 / \mathrm{adfm} .201606813$

URL: http://dx.doi.org/10.1002/adfm.201606813

To cite this version: Létiche, Manon and Brousse, Kevin and Demortiere, Arnaud and Huang, Peihua and Daffos, Barbara and Pinaud, Sébastien and Respaud, Marc and Chaudret, Bruno and Roussel, Pascal and Buchaillot, Lionel and Taberna, Pierre-Louis and Simon, Patrice and Lethien, Christophe Sputtered titanium carbide thick film for high areal energy on chip carbon-based micro-supercapacitors. (2017) Advanced Functional Materials, vol. 27 (n 20). pp. 1606813/1-1606813/10. ISSN 1616-301X

Any correspondence concerning this service should be sent to the repository administrator: staff-oatao@ listes-diff.inp-toulouse.fr 


\title{
Sputtered Titanium Carbide Thick Film for High Areal Energy on Chip Carbon-Based Micro-Supercapacitors
}

\author{
Manon Létiche, Kevin Brousse, Arnaud Demortière, Peihua Huang, Barbara Daffos, \\ Sébastien Pinaud, Marc Respaud, Bruno Chaudret, Pascal Roussel, Lionel Buchaillot, \\ Pierre Louis Taberna, Patrice Simon, and Christophe Lethien*
}

The areal energy density of on-chip micro-supercapacitors should be improved in order to obtain autonomous smart miniaturized sensors. To reach this goal, high surface capacitance electrode $\left(>100 \mathrm{mF} \mathrm{cm}^{-2}\right)$ has to be produced while keeping low the footprint area. For carbide-derived carbon (CDC) micro-supercapacitors, the properties of the metal carbide precursor have to be fine-tuned to fabricate thick electrodes. The ad-atoms diffusion process and atomic peening effect occurring during the titanium carbide sputtering process are shown to be the key parameters to produce low stress, highly conductive, and thick TiC films. The sputtered TiC at $10^{-3} \mathrm{mbar}$ exhibits a high stress level, limiting the thickness of the TiC-CDC electrode to $1.5 \mu \mathrm{m}$ with an areal capacitance that is less than $55 \mathrm{mF} \mathrm{cm}{ }^{-2}$ in aqueous electrolyte. The pressure increase up to $10^{-2}$ mbar induces a clear reduction of the stress level while the layer thickness increases without any degradation of the TiC electronic conductivity. The volumetric capacitance of the TiC-CDC electrodes is equal to $350 \mathrm{~F} \mathrm{~cm}^{-3}$ regardless of the level of pressure. High values of areal capacitance $\left(>100 \mathrm{mF} \mathrm{cm}^{-2}\right)$ are achieved, whereas the TiC layer is relatively thick, which paves the way toward high-performance micro-supercapacitors.

\section{Introduction}

Miniaturized and compact electrochemical energy storage devices were intensively studied during the last decade, opening a new way into the development of autonomous, sustainable, and connected devices. Carbon- ${ }^{[1]}$ and redox-based micro-supercapacitors (MSC) are promising candidates for high power density devices in which a peak of current should lead to a rapid power delivery. ${ }^{[2]}$ Contrary to the charge storage process in MSC, ${ }^{[3-5]}$ which is based on a fast faradic reaction at the near surface of pseudocapacitive electrodes, electrochemical double layer supercapacitors (EDLC) store the charge by reversible ion adsorption at the surface of high surface area carbon electrodes. ${ }^{[6]}$ The main technological breakthrough in the fabrication of carbon micro-supercapacitors (EDLC miniaturization) deals with the design of nanoporous carbon electrodes having a
Dr. M. Létiche, L. Buchaillot, Prof. C. Lethien

Institut d'Electronique de Microélectronique et de Nanotechnologies

Université de Lille

CNRS

Centrale Lille

ISEN

Université de Valenciennes

UMR 8520 - IEMN, F-59000 Lille, France

E-mail: christophe.lethien@iemn.univ-lille1.fr

Dr. M. Létiche, P. Roussel

Unité de Catalyse et de Chimie du Solide (UCCS)

Université de Lille

F-59000 Lille, France

Dr. M. Létiche, P. Roussel

CNRS

Centrale Lille

ENSCL

Université d'Artois

UMR 8181 - UCCS, F-59000 Lille, France

Dr. M. Létiche. K. Brousse, A. Demortière, Dr. P. Huang, B. Daffos,

L. Buchaillot, P. L. Taberna, Prof. P. Simon, Prof. C. Lethien

Patrice Simon, Taberna

Réseau sur le Stockage Electrochimique de l'Energie

CNRS FR 3459, 33 rue Saint Leu, 80039 Amiens Cedex, France

\author{
K. Brousse, Dr. P. Huang, B. Daffos, P. L. Taberna, \\ Prof. P. Simon \\ Patrice Simon Centre Interuniversitaire de Recherche \\ et d'Ingénierie des Matériaux (CIRIMAT) \\ CNRS UMR 5085 - Université Paul Sabatier \\ 118 route de Narbonne, 31062 Toulouse, France \\ A. Demortière \\ Laboratoire de Réactivité et Chimie des Solides (LRCS) \\ CNRS UMR 7314 - Université de Picardie Jules Verne \\ 33 rue Saint Leu, 80039 Amiens Cedex, France \\ S. Pinaud, Prof. M. Respaud, B. Chaudret \\ Laboratoire de Physique et Chimie des Nano Objets \\ LPCNO \\ UMR 5215 INSA-UPS-CNRS \\ Université de Toulouse \\ 31077 Toulouse, France \\ S. Pinaud, Prof. M. Respaud, B. Chaudret \\ Institut National des Sciences Appliquées \\ 135 avenue de Rangueil, 31077 Toulouse, France \\ Prof. M. Respaud \\ AIME \\ Université de Toulouse \\ INSA, UPS, INP \\ 135 avenue de Rangueil, 31077 Toulouse Cedex 4, France
}

DOI: 10.1002/adfm.201606813 
strong adhesion onto the current collector. Nowadays, the ultimate goal is to significantly improve the areal energy density of such MSC up to $50 \mu \mathrm{Wh} \mathrm{cm} \mathrm{c}^{-2}$ (interdigitated configuration) while keeping a surface power density higher than $1 \mathrm{~mW} \mathrm{~cm}{ }^{-2}$. A large variety of materials is studied for designing carbon MSC electrodes such as carbon nanotubes, ${ }^{[7]}$ onion-like carbon, ${ }^{[8]}$ activated carbon, ${ }^{[8]}$ or graphene. ${ }^{[9]}$ Although interesting performances were achieved with such electrodes, some real drawbacks in terms of adhesion of carbon material and of areal energy density remain to be overcome. For carbide-derived carbon layers, nanoporous carbon material issued from the chlorination of a metal carbide ${ }^{[10-13]}$ thin film is a promising solution to fulfill the requirements. The chlorination of sintered titanium carbide ( $\mathrm{TiC}$ ) ceramic plates clearly shows strong adhesion between the $\mathrm{TiC}$ and TiC-CDC layers as well as high volumetric capacitance $\left(170 \mathrm{~F} \mathrm{~cm}^{-3}\right)$ in organic electrolyte $(1 \mathrm{M}$ $\mathrm{NEt}_{4} \mathrm{BF}_{4}$ in acetonitrile). However, a low volumetric capacitance $\left(35 \mathrm{~F} \mathrm{~cm}^{-3}\right.$ ) was reported when using sputtered TiC thin films deposited (1.6 $\mu \mathrm{m}$ thick) on a silicon wafer. ${ }^{[14]}$ We have recently solved the adhesion problem of CDC thin films on a silicon wafer, providing on-chip MSC fabricated at the wafer level with the best tradeoff between areal energy and power densities ever reported..$^{[1]}$ A fine-tuning of the TiC sputtered layers is required to reach this goal and thus produce dense, stress free, and highly conductive thick films. In this paper, we report a methodology to achieve the sputtering deposition of dense titanium carbide thick films for on-chip MSC. In this purpose, the growth mechanisms leading to the film densification are thoroughly studied. The densification of the titanium carbide layers arises both from the atomic peening effect, which causes local atomic displacements at the TiC surface, and from the ad-atoms diffusion into the grain boundaries during the deposition. ${ }^{[15,16]}$ As a consequence of the densification process, the compressive stress ${ }^{[17]}$ has been fully controlled to produce TiC thick films, which are able to sustain the chlorination process used to fabricate TiC-CDC electrodes. Whilst most of the published results focus on the reactive sputtering of titanium target in $\mathrm{Ar} / \mathrm{CH}_{4}$ atmosphere, ${ }^{[18-22]}$ we report here the deposition of thick titanium carbide layers using a nonreactive direct current magnetron sputtering process (DC-MS) on silicon ( $\mathrm{Si}$ ) or $\mathrm{Si} / \mathrm{SiO}_{2}$ wafers. The evolution of the electrical, structural, and morphological TiC properties is proposed as a function of the operating pressure and temperature. We demonstrated here that the stress of the sputtered TiC films (from 0.5 up to $22 \mu \mathrm{m}$ thick) can be finely tuned by careful control of the temperature/pressure deposition parameters. Low and high stress titanium carbide films were successively chlorinated. Electrochemical analyses point out that the tuning of the sputtered $\mathrm{TiC}$ parameters have a weak impact onto the volumetric capacitance of the TiC-CDC electrode, while this tuning is a critical issue to produce thick, stress-free, and highly conductive layers. Although MSCs are surface-dependent devices, the areal capacitance of CDC electrodes is significantly improved by using thick CDC layers.

\section{Results and Discussion}

For the deposition of highly dense TiC layer, we have to study the influence of the deposition parameters (Figure 1A) on the mechanical strength, resistivity, and thickness of sputtered TiC films. Stress-free and thick TiC films $(>1 \mu \mathrm{m})$ must be indeed achieved to prepare porous carbon (CDC) electrodes for microsupercapacitor applications. Thick TiC films with a strong adhesion with a silicon wafer are chlorinated to produce carbon electrodes (Figure 1B). These films have to be dense enough to ensure high areal $\left(\mathrm{mF} \mathrm{cm} \mathrm{cm}^{-2}\right)$ and volumetric capacitance (F per Cc) of the CDC films. Nevertheless, the stress is known to be high in dense films and it has to be controlled to produce thick and high surface capacitance carbon electrodes. ${ }^{[15]}$

Two main contributions drive the mechanical stress level in the sputtered TiC films: the deposition temperature and the deposition pressure. These parameters drastically affect the texture of the $\mathrm{TiC}$ films, ${ }^{[17,23,24]}$ and the film growth is well known to follow the structure zone models (SZM) reported by Thornton. ${ }^{[25]}$ Regarding the required morphology, low deposition pressure and high deposition temperature are crucial parameters to produce dense and thick sputtered TiC films in which the morphologies are found to be in Zone $\mathrm{T}$, Zone 2, or 3 (Figure 1) based on the used terminology in SZM. Low-density fibrous or columnar films with voids between the columns (Zone 1) are not suitable candidates for reaching high areal or volumetric capacitance. TiC layers were deposited using various sputtering deposition conditions (temperature, pressure, and thickness (deposition time)) and characterized to find the suitable parameters for CDC electrodes.

\subsection{Influence of the Deposition Temperature}

X-ray diffraction (XRD) analysis was performed on thin films deposited from room temperature (RT) up to $750{ }^{\circ} \mathrm{C}$ (Figure 2A). In these experiments, the DC power, the pressure, the argon flow, and the deposition time were kept steady close to $2 \mathrm{~W} \mathrm{~cm}^{-2}, 10^{-3} \mathrm{mbar}, 100 \mathrm{sccm}$, and $1800 \mathrm{~s}$, respectively. The film thickness was measured around $0.4 \mu \mathrm{m}$. Figure 2A shows that all the sputtered thin films are crystallized, regardless of the deposition temperature. At first approximation, diffraction peaks could be indexed with the International Center for Diffraction Data (ICDD) powder diffraction file 00-032-1383 associated to a rock salt-type ( $\mathrm{NaCl}$ type) face-centered cubic system (fcc-space group Fm-3m). The carbon atoms are localized in such structure on the octahedral sites of the titanium lattice. The peaks identified at $\approx 35.6^{\circ}, \approx 41.2^{\circ}, \approx 60.4^{\circ}, \approx 72.5^{\circ}$, and $\approx 76.2^{\circ}$ correspond to the (111), (200), (220), (311), and (222) diffraction planes of a titanium carbide polycrystalline thin film, respectively. The top surface analysis of the sputtered $\mathrm{TiC}$ thin films was made by using atomic force microscopy (AFM) (Figure 2B) on a scanning area of $1 \mu \mathrm{m}^{2}$. Sample roughness appears to be relatively low, close to $0.6 \mathrm{~nm}( \pm 0.1 \mathrm{~nm})$, regardless of the deposition temperature. Contrary to Zoita and co-workers, who reported an epitaxial growth of TiC on $\mathrm{MgO}$ substrate, ${ }^{[21]}$ no epitaxial growth of the titanium carbide thin films on silicon wafer was observed as a consequence of the large lattice mismatching between the silicon wafer and the TiC thin films (lattice constants of 4.32 and $5.43 \AA$ for the $\mathrm{TiC}$ and $\mathrm{Si}$, respectively). A preferential orientation is, however, observed (Figure 2C) since the (111)/ (200) intensity ratio changes from 1.5 (RT deposition) up to 20 (750 ${ }^{\circ} \mathrm{C}$ deposition) for $0.4-\mu \mathrm{m}$-thick sputtered TiC films. As the 


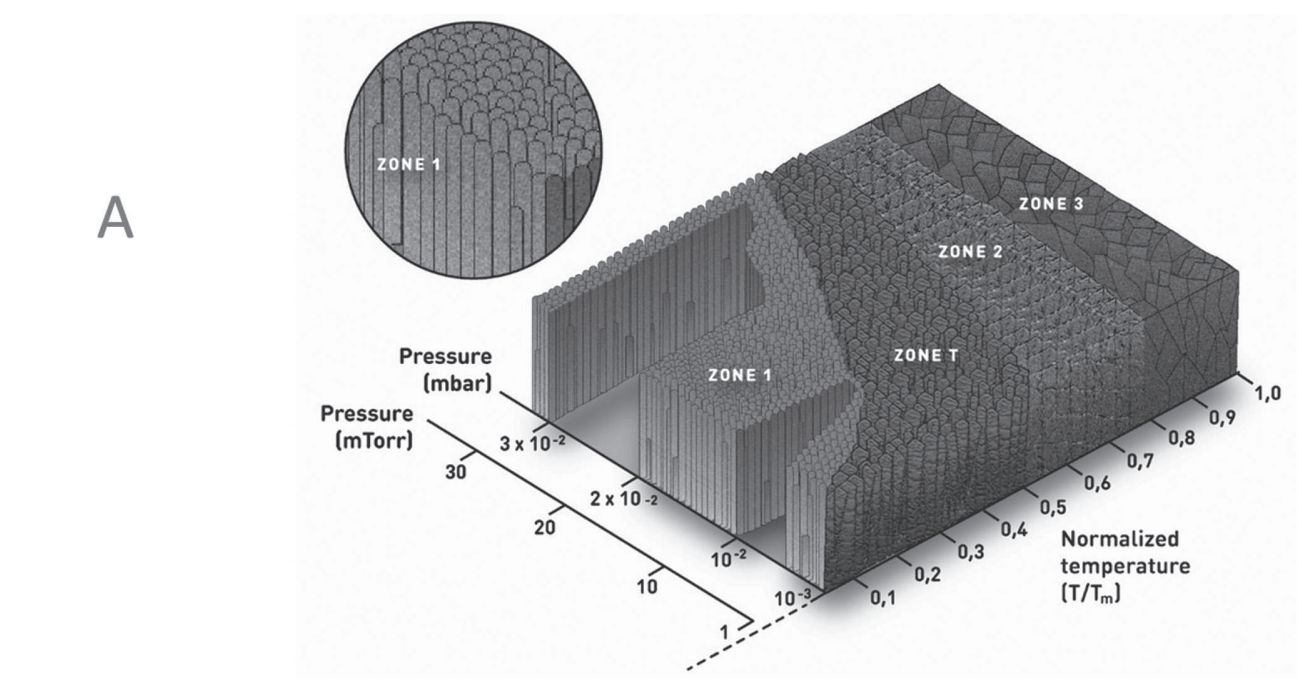

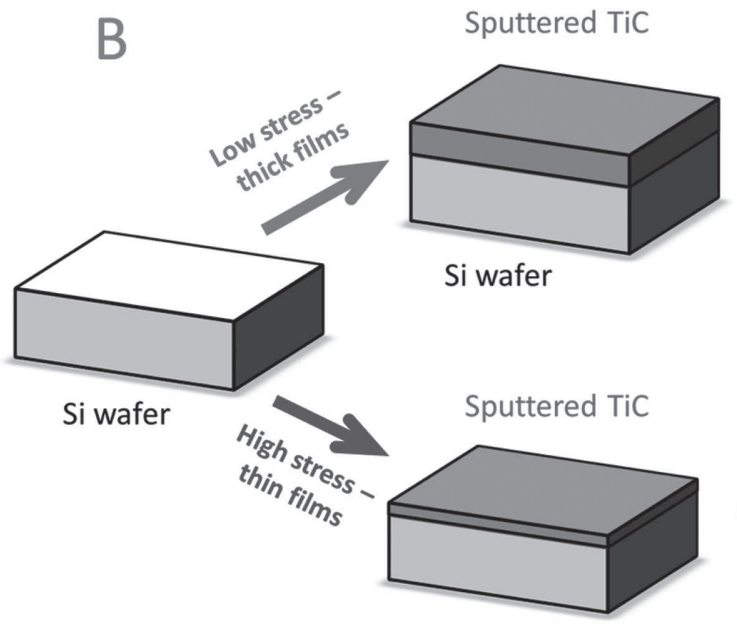

Si wafer

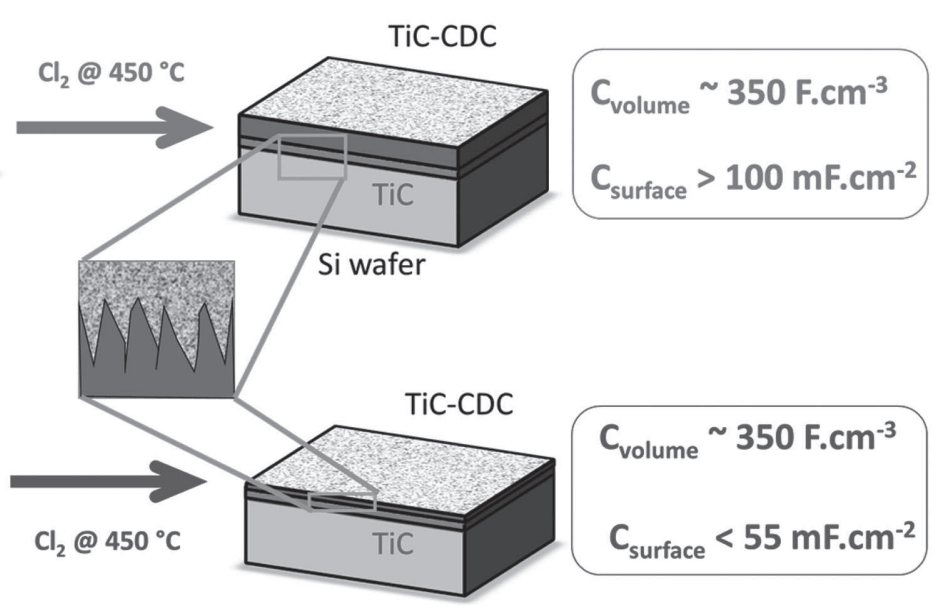

Si wafer

Figure 1. A) Structure zone model of sputtered thin films as a function of the deposition pressure (in $\mathrm{mTorr}$ or $\mathrm{mbar}$ ) and $T / T_{\text {melting }}$ ratio (adapted from Thornton ${ }^{[25]}$. The morphology of the sputtered thin films has been tuned according to the temperature and the deposition pressure parameters. B) Overview of the proposed strategy to perform the fabrication of strongly adhesive, stress-free, highly conductive, thick TiC films and high areal capacitance TiC-CDC electrodes.

thickness and the pressure were kept steady for all samples, the raised thermal energy (from 25 to $88 \mathrm{meV}$ ) due to the substrate heating (from RT up to $750{ }^{\circ} \mathrm{C}$ ) improves the mobility of ad-atoms. This explains the subsequent faster growth ${ }^{[26]}$ of the (111) diffraction versus (200) planes. Based on a higher diffusion of the ad-atoms at $750{ }^{\circ} \mathrm{C}$, the film densification occurs via a diffusion process ${ }^{[15,27,28]}$ in which ad-atoms are incorporated into the grain boundaries during the sputtering deposition.

Two main contributions influence the mechanical stress generated in a thin film: the thermal stress and the intrinsic stress. The thermal stress is predominant ${ }^{[16]}$ during the sputtering deposition at high $T / T_{\mathrm{m}}$ (where $T_{\mathrm{m}}$ is the melting temperature). TiC thin films ( $\left.T_{\mathrm{m}}=3340 \mathrm{~K}\right)$ is deposited by sputtering at $T / T_{\mathrm{m}}<0.4$, which is in the middle of the transition zone (Zone T) from the Thornton ${ }^{[29,30]}$ SZM (Figure 1A). Below 0.4, the intrinsic stress mainly depends on the sputtering deposition conditions and particularly the deposition pressure that turns out to be the main tuned parameter.

\subsection{Influence of the Deposition Pressure}

\subsubsection{Evolution of the Film Stress}

The pressure ${ }^{[15]}$ is the crucial parameter in the control of the ion peening effect and thus in the intrinsic stress within the thin films, which is an important issue for the thick films. Equation (1) gives the film stress $\left(\sigma_{\text {film }}\right)$, which is the sum of the contribution of the thermal stress $\left(\sigma_{\text {thermal }}\right)$ and growth stress $\left(\sigma_{\text {growth }}\right)$ associated with the film morphology and texture

$$
\begin{aligned}
\sigma_{\text {film }} & =\sigma_{\text {thermal }}+\sigma_{\text {growth }} \\
& =\left(\alpha_{\mathrm{TiC}}-\alpha_{\mathrm{Si}}\right) \cdot\left(T_{\text {deposition }}-T_{\text {meas-stress }}\right) \cdot \frac{E_{\mathrm{TiC}}}{1-v_{\mathrm{TiC}}}+\sigma_{\text {growth }}
\end{aligned}
$$

where the thermal stress $\sigma_{\text {thermal }}$ can be estimated from the thermal expansion coefficients of the TiC film 

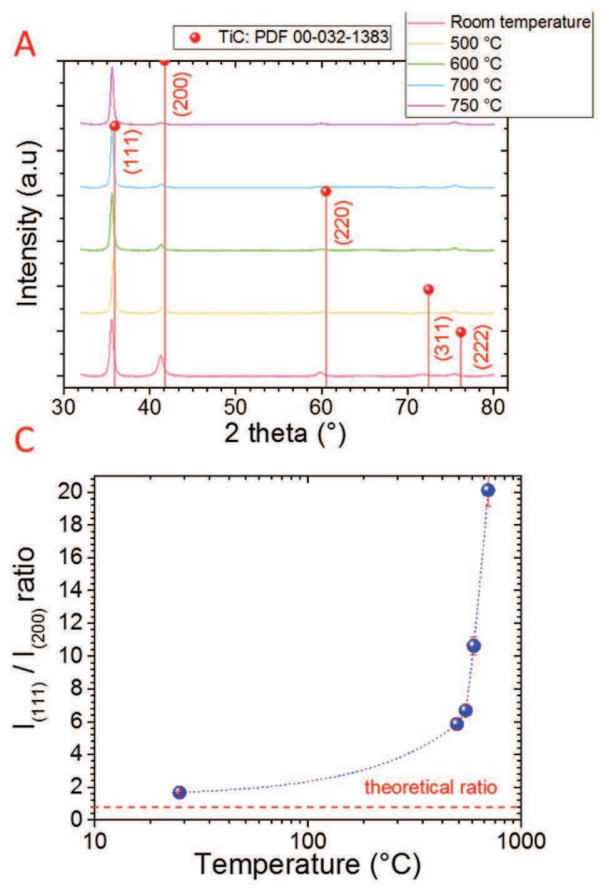

B

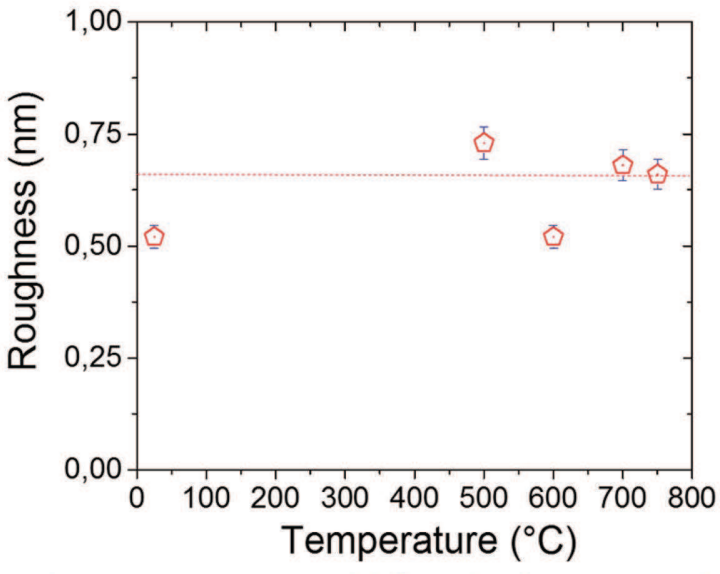

$\mathrm{RT}-0.5 \mathrm{~nm}$



$500{ }^{\circ} \mathrm{C}-0.73 \mathrm{~nm}$

$750^{\circ} \mathrm{C}-0.66 \mathrm{~nm}$

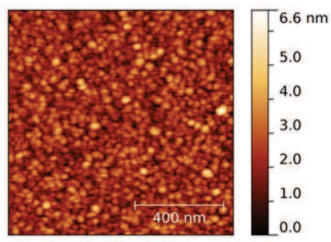

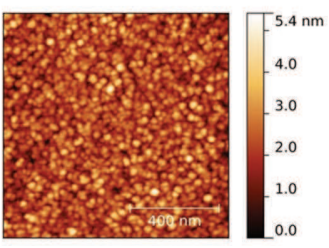

Figure 2. Evolution of the sputtered titanium carbide thin film morphologies with the deposition temperature. In all these experiments, the deposition pressure is kept very low, close to $10^{-3} \mathrm{mbar}$. The DC power as well as the deposition time is kept constant (150 W and $1800 \mathrm{~s}$, respectively). A) Diffractograms of the sputtered thin films deposited at room temperature, $500,600,700$, and $750{ }^{\circ} \mathrm{C}$, respectively. All the deposited thin films $(0.4 \mu \mathrm{m}$ thick) are identified to the PDF 00-032-1383 card and no shift of the diffraction peaks is highlighted as a function of the deposited temperature. B) Top surface analysis of the TiC layers (AFM) at different temperatures. Whatever the deposition temperature, the roughness is kept close to $0.6 \pm 0.1 \mathrm{~nm}$. Regarding this surface analysis, the deposited thin films clearly show a dense and columnar morphology. C) Evolution of the (111)/(200) intensity ratio as a function of the deposited temperature: the preferential orientation of the (111) diffraction plane is clearly depicted on this graph.

$\left(\alpha_{\mathrm{TiC}}=7.5 \times 10^{-6}{ }^{\circ} \mathrm{C}^{-1}\right)$ and the silicon wafer $\left(\alpha_{\mathrm{Si}}=3 \times 10^{-6}{ }^{\circ} \mathrm{C}^{-1}\right)$, the Poisson coefficient $\left(v_{\mathrm{TiC}}=0.3\right)$, and Young modulus $E_{\mathrm{TiC}}$ $(187 \pm 11 \mathrm{GPa}$, measured by nanoindentation on several samples) of the TiC film. For the sputtering, deposition of the film is achieved at room temperature $\left(T_{\text {deposition }}=50^{\circ} \mathrm{C}\right)$, taking into account the heating ${ }^{[31]}$ of the substrate owing to ionic bombardment of sputtered particles, the thermal stress $\sigma_{\text {thermal }}$ is estimated at about $30 \mathrm{MPa}\left(T_{\text {meas-stress }}=25^{\circ} \mathrm{C}\right)$. As the intrinsic stress is known ${ }^{[17]}$ to be higher than $-5000 \mathrm{MPa}$ (compressive contribution), the thermal stress can be assumed to be negligible and $\sigma_{\text {film }} \approx \sigma_{\text {growth }}$.

Both the diffusion process and atomic peening effect have the same consequence on the densification of thin films but are different in nature. The deposition temperature (and thus the $T / T_{m}$ ratio) allows control of the ad-atoms mobility (diffusion process). The pressure affects the kinetic energy (ion peening) of the incoming atoms striking the films under growth, which causes a local displacement at the atomic scale. These two parameters correspond to the $x$ and $y$ axis of the Figure 1A.

Figure S1 (Supporting Information) shows the top surface and cross-section analyses of the sputtered TiC films deposited at room temperature, in which no film densification due to ad-atoms diffusion process is possible. As expected, film morphologies are consistent with the SZM proposed in the literature. ${ }^{[30,32,33]}$ At high pressure $\left(10^{-1} \mathrm{mbar}\right)$, porous or/ and fibrous film morphology is clearly depicted (Figure S1C,
Supporting Information). The film densification occurs as soon as the pressure is decreased down to $10^{-3}$ mbar due to the ion peening effect ${ }^{[16]}$ (Zone $\mathrm{T}$, Figure $1 \mathrm{~A}$ ). In the zone $\mathrm{T}$ at room temperature, the film is allowed to grow only at very low deposition pressure. Such densification mechanism is favorable for the preparation of dense TiC layers (Figure S1A, Supporting Information) as precursors of dense porous CDC films. However, the intrinsic growth stress has to be carefully controlled in order to produce thick films. The roughness analysis clearly confirms the densification process of the sputtered TiC. Indeed, the porous structure (high roughness) is progressively filled by atoms resputtering, a process occurring due to ion peening (low roughness).

In Figure 3 is presented the X-ray diffraction analysis of the sputtered titanium carbide thin films deposited at RT as a function of the deposition pressure, from $10^{-3}$ to $10^{-1} \mathrm{mbar}$. All of the diffractograms (Figure 3A) could be fitted using a TiC single-phase and polycrystalline thin film with different orientations.

A detailed analysis (Figure 3B) of the XRD pattern reveals a continuous shift of the lattice parameter as a function of the deposition pressure and a crystal cell distortion. Indeed, it is not possible to account for all the peaks in a cubic symmetry; hence, either a quadratic or a rhombohedral crystalline structure (Figure 3C and Figure S2, Supporting Information) should be used for the pattern fitting. The evolution of the crystalline cell volume in tetragonal symmetry is reported in Figure 3B. 

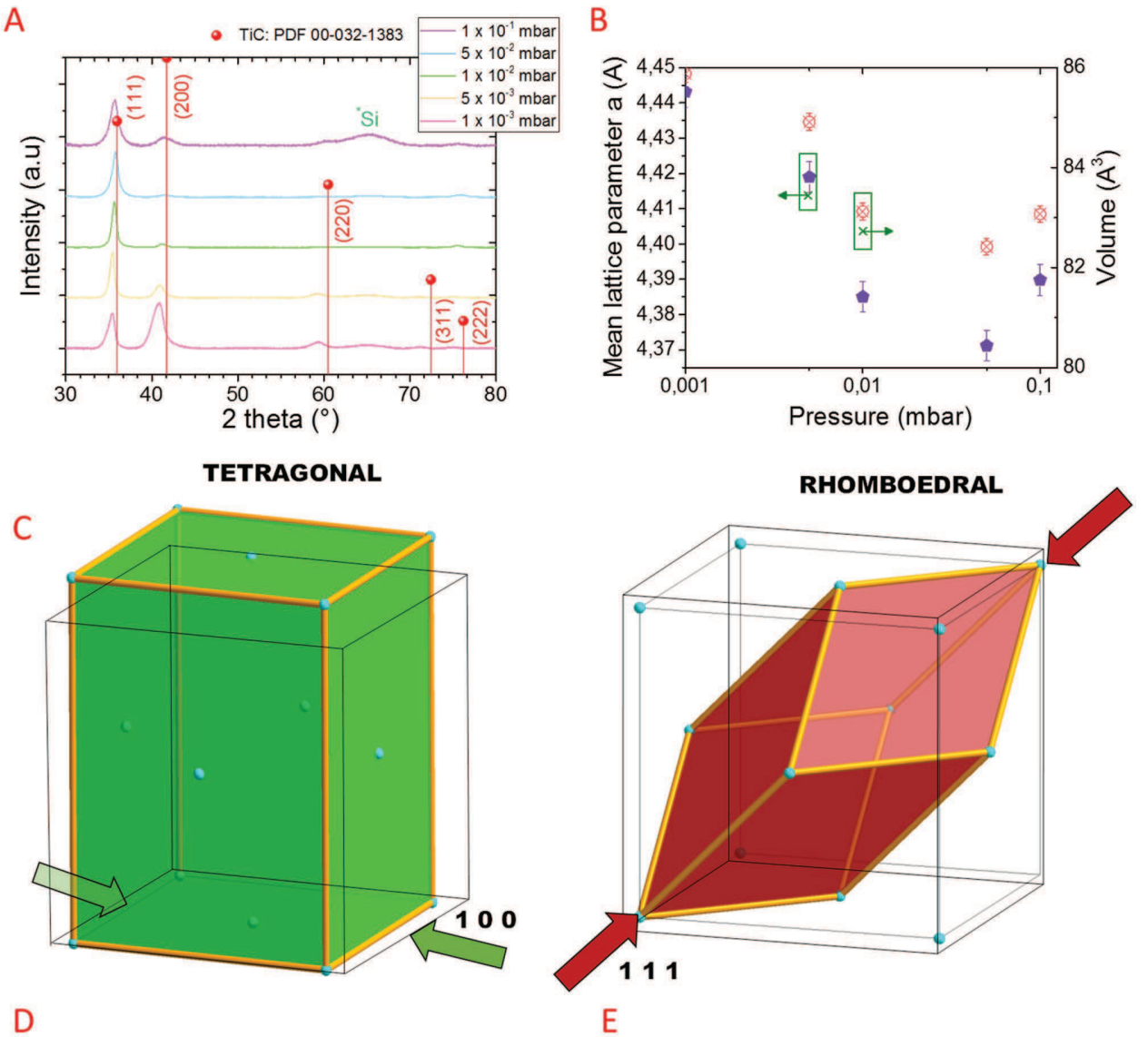

D
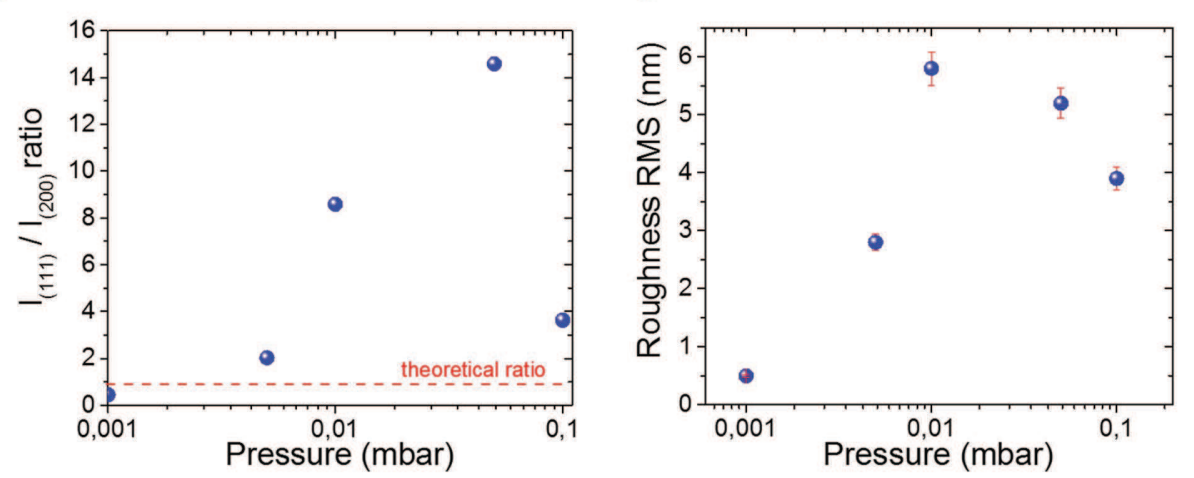

Figure 3. Evolution of the properties of the TiC thin film as a function of the deposition pressure. The pressure is the main tuned parameter to control the film morphology. The kinetic energy of the sputtered particles is directly linked to the atomic or ion peening effect that has led to the formation of compressive stress layers. A) Diffractograms of the TiC thin films as a function of the deposition pressure. A shift of the diffraction peaks is depicted on these graphs. The film stress seems to be responsible for this shift. B) Mean lattice parameter and volume of the tetragonal unit cell versus pressure. C) Illustration of the crystal cell deformation, from a cubic to tetragonal or rhombohedral structure. D) Evolution of the preferential orientation as a function of the deposition pressure. E) Roughness (scanning area $=1 \mu \mathrm{m} \times 1 \mu \mathrm{m}$ ) as a function of the deposition pressure.

A similar conclusion ${ }^{[21]}$ was already reported on TiC epitaxially grown on $\mathrm{MgO}$ substrate.

The XRD analysis reveals a preferential orientation (Figure $3 \mathrm{D}$ ) of the film along the [111] direction when the pressure is increased from $10^{-3}$ to $10^{-1}$ mbar. The change in the roughness as a function of the pressure (Figure 3E) is as expected, ${ }^{[15]}$ since it varies from 0.5 to $5 \mathrm{~nm}$, respectively, for deposition pressures of $10^{-3}$ and $10^{-2}$ mbar. The film mechanical stress and the film resistivity are known to be highly dependent on the deposition pressure (Figure 4A). The Stoney equation (Equation (2)) was used to calculate the intrinsic stress $\sigma_{\text {growth }}(<0$ for compressive stress and $>0$ for tensile one) during the growth of sputtered $\mathrm{TiC}$ at room temperature (sputtering time $=1800 \mathrm{~s}$ ).

$\sigma_{\text {growth }}=\frac{1}{6} \cdot \frac{E_{\mathrm{Si}}}{1-v_{\mathrm{Si}}} \cdot \frac{t_{\mathrm{Si}}^{2}}{t_{\mathrm{TiC}}} \cdot\left(\frac{1}{R_{\mathrm{TiC}}}-\frac{1}{R_{\mathrm{Si}}}\right)$

where $E_{\mathrm{Si}}, v_{\mathrm{Si}}, t_{\mathrm{Si}}$, and $R_{\mathrm{Si}}$ are, respectively, the Young modulus $(131 \mathrm{GPa})$, the Poisson coefficient $(0.27)$, the thickness 

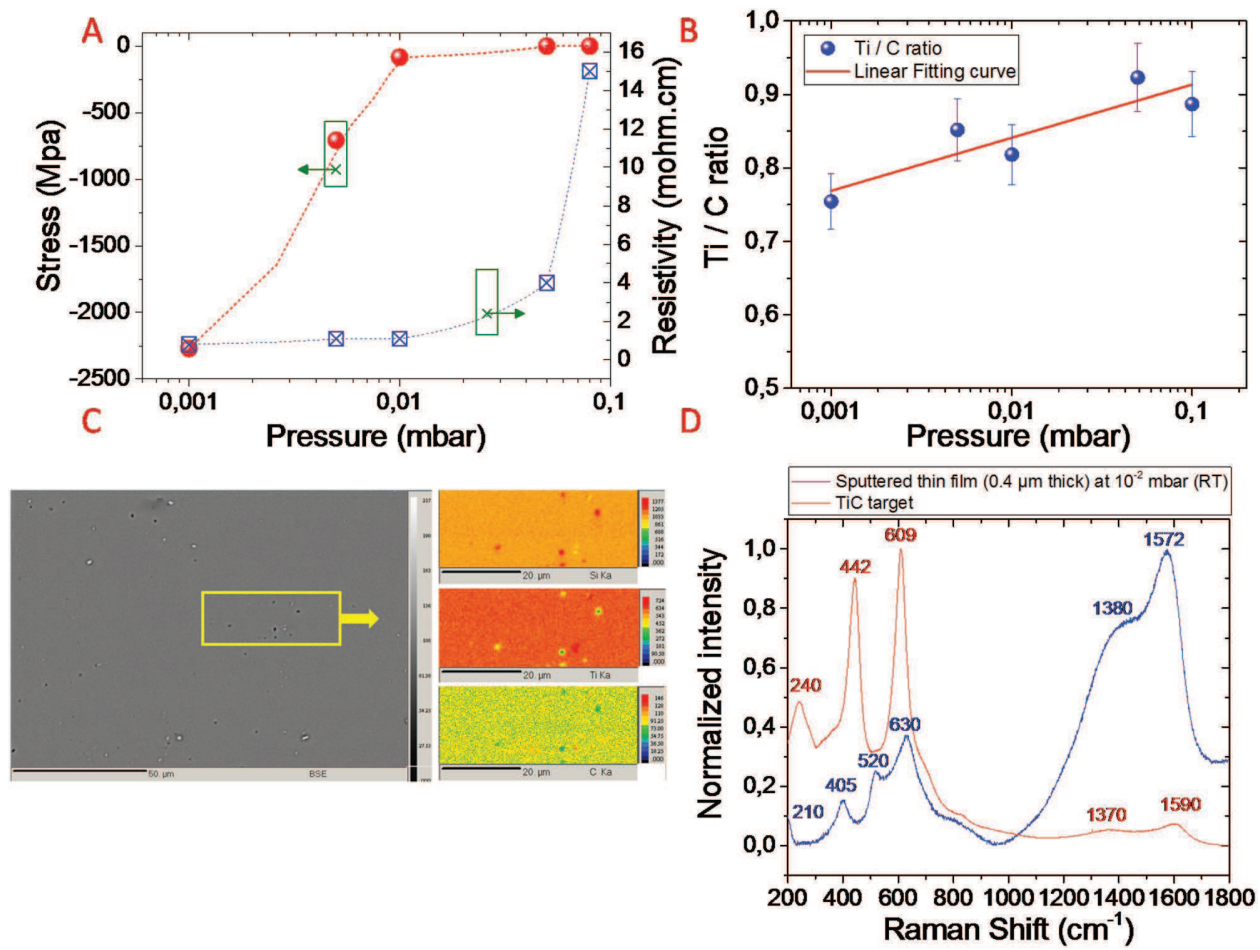

Figure 4. A,B) Change of stress, resistivity, and Ti/C ratio as a function of the deposited pressure. C) Top surface mapping of TiC thin film performed by WDS. D) Raman spectroscopy of the TiC target and the sputtered thin film at 0.01 mbar.

(380 $\pm 10 \mu \mathrm{m}$ ), and the bending radius (in meters) of a typical (100) silicon wafer. The film thickness $\left(t_{\mathrm{TiC}} \# 0.4 \mu \mathrm{m}\right)$ was measured using a scanning electron microscope (SEM) (cross sections analysis). The bending radius of the $\mathrm{TiC}\left(R_{\mathrm{TiC}}\right)$ was measured just after the sputtering deposition and compared with the one $\left(R_{\mathrm{Si}}\right)$ before the deposition.

\subsubsection{Evolution of the Film Resistivity and the Film Composition as a Function of the Pressure}

The film densification occurring at low pressure $\left(10^{-3} \mathrm{mbar}\right)$ leads to a significant increase of the compressive stress $(-2200 \mathrm{MPa})$, which is not favorable for a thicker film deposition. In the same range of sputtered TiC films issued from TiC target, ${ }^{[23]}$ these high-stress sputtered TiC thin films are highly conductive with a resistivity (Figure 4A) close to $0.3 \mathrm{~m} \Omega \mathrm{cm}$. As a result of the increase of the pressure from $10^{-3}$ to $10^{-2} \mathrm{mbar}$, the compressive stress of the titanium carbide layer decreases $(-130 \mathrm{MPa})$. The slight decrease of the electrical conductivity is usually ascribed to a larger amount of defect, porosity, or grain boundaries. ${ }^{[19]}$ This is even more clear at higher pressure $\left(10^{-1} \mathrm{mbar}\right)$, under which the stress is constant and the resistivity increases to $15 \mathrm{~m} \Omega \mathrm{cm}$ due to the porous morphology of the columnar growth (Figure S1C, Supporting Information). The change of the film composition versus the operating pressure is reported in Figure 4B. The Ti/C ratio changes linearly with the pressure and reaches 0.8 at $10^{-2}$ mbar. The change of $\mathrm{Ti} / \mathrm{C}$ ratio $(0.75 \rightarrow 0.8)$ (from $10^{-3}$ to $10^{-2} \mathrm{mbar}$ ) could also explain the slight decrease of the electrical conductivity. ${ }^{[34]}$ The atomic content of carbon is about $55 \% \pm 2$ in most of the TiC films. According to the phase diagram ${ }^{[35]}$ of the TiC, two different phases coexist between 500 and $3000{ }^{\circ} \mathrm{C}$ for a carbon content higher than $48 \%$ : a TiC phase and a carbon one. As a result, wavelength dispersive spectroscopy (WDS) analysis (Figure 4B,C) shows few carbon particles. The absence of any additional peak in the XRD patterns confirms the amorphous or weakly crystallized nature of the carbon particles. Figure 4D shows the Raman spectra of the TiC target and the 0.4- $\mu \mathrm{m}$-thick TiC films deposited at $10^{-2}$ mbar. The TiC target exhibits two sets of peaks: the first set with strong peaks intensity at 240, 440 , and $609 \mathrm{~cm}^{-1}$ corresponds to the TiC. Smaller peaks at 1370 and $1570 \mathrm{~cm}^{-1}$ are attributed to the $\mathrm{D}$ band and $\mathrm{G}$ band of carbon. Similar features were observed for the sputtered TiC thin film. Three peaks at low Raman shift are attributed to the TiC thin film. The additional peak at $520 \mathrm{~cm}^{-1}$ corresponds here to the silicon substrate. Strong peaks measured at 1380 and $1570 \mathrm{~cm}^{-1}$ are assigned to the excess of carbon (carbon phase) in the TiC layer. A similar behavior was observed regardless of the deposition pressure. The argon flow applied during the deposition process does not significantly affect the TiC properties (Figure S3, Supporting Information).

In summary from the study of sputtered $0.4 \mu \mathrm{m}$ thick TiC films, it turns out that a deposition temperature of $750{ }^{\circ} \mathrm{C}$ under an operating pressure of $10^{-2}$ mbar leads to the formation of dense, low stress, electrically conducting TiC films. These deposition parameters were selected to prepare thicker TiC films $(>1 \mu \mathrm{m})$. To gain a better insight into the growth mechanism of sputtered titanium carbide thin films, a study was carried out on the two processes leading to the film densification (ad-atoms diffusion process and ion peening effect). This in depth study onto the sputtered titanium carbide 
material is really meaningful to pave the way toward the growth of strongly bonded metal carbide thick films on silicon wafer. The thickness of the titanium carbide layers was progressively increased. Based on the sputtering conditions $\left(10^{-2} \mathrm{mbar}, T=\right.$ $750{ }^{\circ} \mathrm{C}$ so $\mathrm{T} / T_{\mathrm{m}}=0.3$ ), the film morphology was found to exhibit a dense and columnar morphology. Moving to higher pressure $\left(10^{-1} \mathrm{mbar}\right)$ seems to be an interesting way to produce thicker layers (stress-free layers). However, the high resistivity and porous morphology of the films are not suitable for preparing strongly bonded carbon films with high volumetric/surface capacitances after chlorination. ${ }^{[14]}$

\subsection{Increase of the Film Thickness}

Figure S4 (Supporting Information) shows the film properties as a function of the thickness. XRD analysis (Figure S4A,B, Supporting Information) reveals first that the main diffraction peaks do not shift toward lower or higher 2 theta value, meaning that the stress does not influence the lattice parameter for such thick films. The $I_{(111)} / I_{(200)}$ intensity ratio clearly shows a (111) preferential orientation of the TiC layers at low thickness $(<2 \mu \mathrm{m}$ thick). For thicker films, the intensity ratio tends to the theoretical value of 1 . The thickness and the roughness were measured as a function of the deposition time (Figure S4C, Supporting Information). The deposition rate appears to be close to $0.9 \mu \mathrm{m} \mathrm{h}^{-1}$ when considering the operating deposition parameters $\left(P_{\mathrm{DC}}=150 \mathrm{~W}\right.$, Ar flow $=100 \mathrm{sccm}$, pressure $=10^{-2} \mathrm{mbar}$, and temperature $=750{ }^{\circ} \mathrm{C}$ ). As expected, the roughness is increased from 1 to $150 \mathrm{~nm}$ for thicker TiC layer, in the range of $1 \%$ of the thickness layer.

The film morphology was investigated as a function of the thickness and the values are reported in Figure S5 (Supporting Information). The AFM top surface and SEM cross-section analyses were combined to study the film morphologies. A large scanning area is taken into account to get a good overview of the TiC surface $(20 \mu \mathrm{m} \times 20 \mu \mathrm{m})$ and thus a good approximation of the surface roughness (Figure S5, Supporting Information). As expected, a thicker TiC layer induces a larger column diameter. This is consistent with a columnar growth of metal carbide in the Zone $\mathrm{T}$ (Figure 1).

TEM investigation performed on TiC deposited at $10^{-2}$ mbar shows the growth evolution of TiC crystals from the Si surface, where randomly oriented nanocrystals were observed as supported by the selected area electron diffraction (SAED) (Figure 5B), to the TiC bulk, in which elongated crystals were formed with structural dislocations (Figure 5C,D). Figure 5G exhibits an elongated TiC structure that forms two boundaries with two crystals oriented along the [111] direction with a relative tilt of $10^{\circ}\left(30^{\circ}\right.$ red area and $20^{\circ}$ green area, respectively), which induces a strain in the structure (Figure $5 \mathrm{H}-\mathrm{J})$. The elongated structure consists of screw dislocations, as observed


Figure 5. TEM characterization of an FIB/SEM cross-section of the Si/TiC/CDC material at different areas. A) TEM image of Si/TiC interface showing the structural evolution of TiC during the growth onto the Si surface with the formation of elongated structures. B-D) Electron diffraction patterns of, respectively, Si/TiC interface (orange square in $(A)$ ) showing spots of right orientated Si structure and rings associated to randomly orientated nanocrystals of TiC (Fm-3m); TiC close to the Si surface (red square in (A)) showing rings with brighter sections revealing the presence of partially orientated structures; TiC elongated structures (blue square in (A)) exhibiting bright arcs which are related to preferential orientations. E) HRTEM image of randomly orientated TiC nanocrystals on the Si surface. F) HRTEM images of elongated TiC crystals. The high-resolution image (G) shows an elongated TiC structure, which form two boundaries with two crystals (111) having different orientations at $\mathrm{H}$ ) $30^{\circ}$ (red area) and J) $20^{\circ}$ (green area), respectively, as shown in the FFT (fast Fourier transform) images. I) Based on the Fourier transform, the TiC crystalline part is consisting of both orientations $\left(20^{\circ}\right.$ and $\left.30^{\circ}\right)$ and presents clear discontinuities, which are associated with structural dislocations. K) Screw dislocations can be observed with clear dislocation lines from which a Burgers vector can be defined (inset). 
in the HRTEM (high resolution transmission electron microscopy) image of Figure 5K. A screw dislocation in the lattice structure is a result of shear stress. The defect line movement is perpendicular to the direction of the stress and the atom displacement. In the inset, the dislocation line and a Burger vector are indicated. After each dislocation line, the structure is shifted of a half of (111) distance and slightly tilted to adapt the strain from $20^{\circ}$ to $30^{\circ}$ in orientation. The screw dislocations break the symmetry of the crystal and produce self-perpetuating steps to enable 1D crystal growth. ${ }^{[36]}$ The presence of an axial screw dislocation distorts the lattice planes, which generates a dark line of contrast, as observed in Figure 5A. This analysis shows that even if the stress level of the sputtered $\mathrm{TiC}$ at $10^{-2}$ mbar is relatively low $(-150 \mathrm{MPa})$, the high thickness of the TiC film leads to screw dislocations, which do not influence the mechanical strength of the TiC for micro-supercapacitor applications.

\subsection{Electrochemical Characterization of the CDC Electrodes}

The power performances of metal oxide MSC based on a thick electrode are impacted by the poor electronic conductivity of the electrodes. Therefore, the binder-free CDC electrodes could be used as thick layers $(<10 \mu \mathrm{m}$ thick) owing to the high conductivity and the open porosity of the carbon materials. For that purpose, the sputtering conditions were optimized to achieve the deposition of thick, stress free, and dense TiC films for micro-supercapacitors applications. First, a $12.5-\mu \mathrm{m}$-thick TiC film deposited at $10^{-2}$ mbar and $750{ }^{\circ} \mathrm{C}$ was studied so as to demonstrate the feasibility of this process. The roughness (scanning area $=50 \mu \mathrm{m} \times 50 \mu \mathrm{m}$ ) appears to be relatively steady about $90 \mathrm{~nm}$ before and after the chlorination (Figure 6A). The mechanical strength of the $12.5 \mu \mathrm{m}$ thick sputtered $\mathrm{TiC}$ is preserved. Hence, the TiC-CDC electrodes clearly exhibit a strong adhesion onto the silicon wafer due to partial chlorination of the sputtered TiC layer. The cross-section of a $12.5 \mu \mathrm{m}$ thick sputtered TiC, which was chlorinated during $6 \mathrm{~min}$, is reported in Figure 6B. The thicknesses of the TiC-CDC electrode (partial chlorination) and the TiC underlayer were measured and are close to 6.7 and $5.8 \mu \mathrm{m}$, respectively. A focus at the TiC-CDC/TiC interface clearly shows that the etched rate of the chlorination process is homogenous as already shown recently. ${ }^{[1]}$ The Raman spectroscopic measurement is reported on Figure 6C before (TiC films) and after (TiC-CDC electrode) the chlorination at $450{ }^{\circ} \mathrm{C}$. It reveals that the chlorination process allows producing an amorphous carbon layer with a high degree of disorder $\left(I_{\mathrm{D}} / I_{\mathrm{G}}=0.77\right)$. Once the fabrication process of thick CDC film is established, the electrochemical performances of CDC electrodes were estimated as a function of the deposition pressure. To carry out such a study, three TiC films (2.6, 3.3, and $5 \mu \mathrm{m}$ thick) deposited at three different pressures $\left(10^{-3}, 5 \times 10^{-3}\right.$, and $10^{-2}$ mbar, respectively) were chlorinated in the same conditions. Low deposition pressure induces high stress within the TiC layer. Consequently, the thickness of the TiC layer is limited to few micrometers. The chlorination rate, i.e., the CDC growth rate, is estimated at $1.1 \pm 0.1 \mu \mathrm{m} \mathrm{min} \mathrm{m}^{-1}$ for sputtered $\mathrm{TiC}$ at $10^{-2} \mathrm{mbar}$ and $0.3 \pm 0.1 \mu \mathrm{m} \mathrm{min}{ }^{-1}$ for the one deposited at $10^{-3}$ mbar. The lower growth rate of the low pressure TiC-CDC sample is probably due to the TiC film densification caused by both ad-atoms diffusion process and ion peening effect. After an annealing of the CDC electrodes (1.5, 1.3 , and $3.2 \mu \mathrm{m}$ thick) under vacuum at $600{ }^{\circ} \mathrm{C}$, the electrochemical performances in aqueous electrolyte $\left(1 \mathrm{M} \mathrm{H}_{2} \mathrm{SO}_{4}\right)$ are reported on Figure 6D,E. Based on the cyclic voltammetry (CV) $\left(5 \mathrm{mV} \mathrm{s}^{-1}\right)$ depicted in Figure 6D, we demonstrate that the deposition pressure does not have a strong influence onto
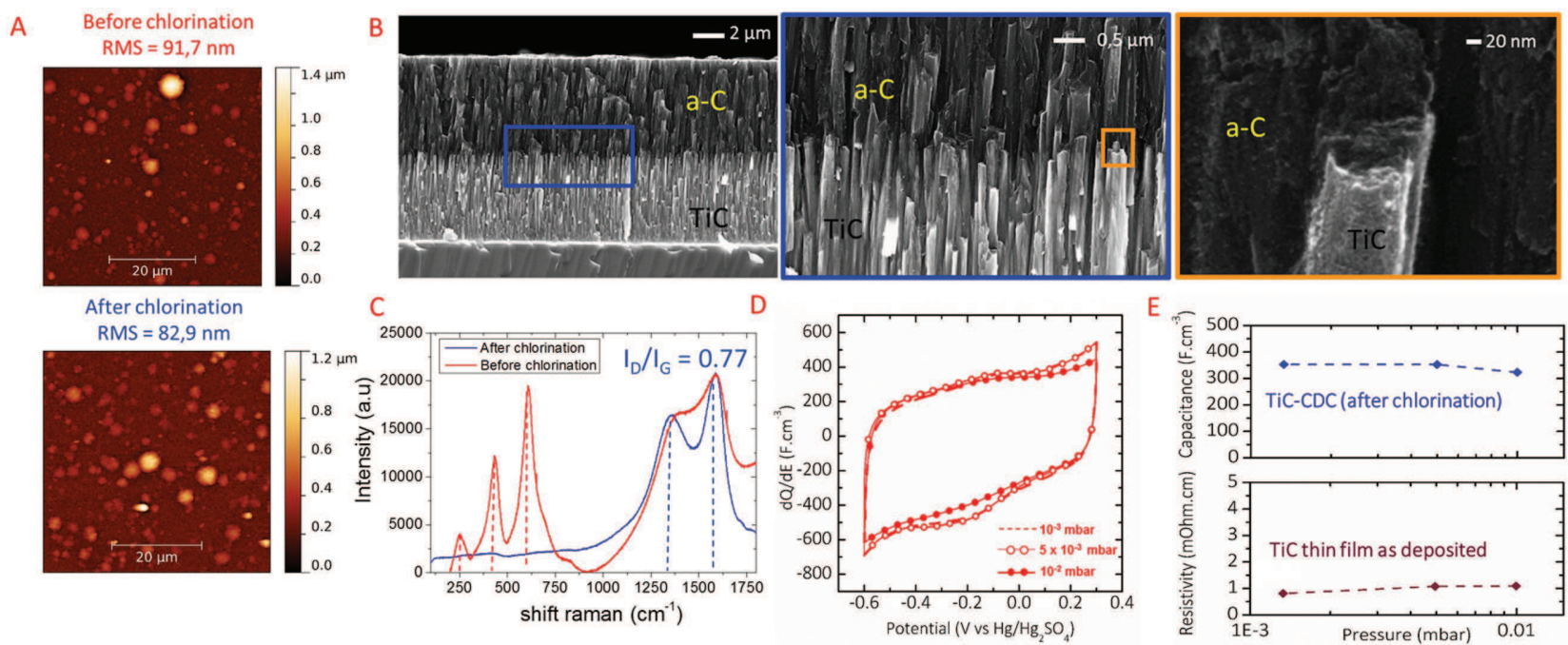

Figure 6. Study of the TiC and TiC-CDC thin films properties as a function of the deposition pressure. A) Evolution of the roughness before and after chlorination: AFM top surface analysis (scanning area $=50 \mu \mathrm{m} \times 50 \mu \mathrm{m}$ ) reveals no change of the roughness (\# $88 \pm 5 \mathrm{~nm}$ ) owing to the chlorination process. B) SEM fracture analysis of $12.5 \mu \mathrm{m}$ thick sputtered TiC layer $\left(10^{-2} \mathrm{mbar}\right.$ and $750^{\circ} \mathrm{C}$ ) chlorinated at $450^{\circ} \mathrm{C}$ during 6 min. C) Raman spectroscopy of sputtered thick films before and after chlorination. The $I_{D} / I_{\mathrm{G}}$ ratio is found to be close to 0.77 . D) Cyclic voltammograms recorded at $5 \mathrm{mV} \mathrm{s}^{-1}$ in $1 \mathrm{M} \mathrm{H}_{2} \mathrm{SO}_{4}$ for on-chip TiC-CDC chlorinated at $450^{\circ} \mathrm{C}$ as a function of the deposition pressure of the TiC thin films ( $10^{-3} \mathrm{mbar}$ (dashed line), $5 \times 10^{-2}$ mbar (open circles) and $1 \times 10^{-2} \mathrm{mbar}$ (solid circles)). E) Change of the resistivity of the sputtered TiC thick films (bottom) and of the volumetric capacitance delivered by the TiC-CDC electrodes (top) with the TiC deposition pressure. 
the CDC performance, reported per $\mathrm{F} \mathrm{cm}^{-3}$, as the three CVs are similar. The volumetric capacitances extracted from these $\mathrm{CV}$ are close to $350 \mathrm{~F} \mathrm{~cm}^{-3}$ (Figure 6E top) regardless of the pressure. This value is similar to that of a recent work..$^{[1]}$ Nevertheless, the meaningful metric for micro-supercapacitors deals with reporting the areal/surface capacitance. In that respect, taking into account a constant volumetric capacitance, one trendy way to improve the surface capacitance is to increase the CDC thickness. If the TiC-CDC thickness is limited by the TiC thickness (and so by the deposition pressure owing to the film stress), there is no reason to attempt to improve the surface performance with a thicker layer.

In this study, the surface capacitance moves from $53 \mathrm{mF} \mathrm{cm}^{-2}$ (TiC $(2.6 \mu \mathrm{m})$ deposited at $10^{3} \mathrm{mbar} \rightarrow \mathrm{CDC}$ $1.5 \mu \mathrm{m}$ thick) to $103 \mu \mathrm{mF} \mathrm{cm}{ }^{-2}$ (TiC $(5 \mu \mathrm{m})$ deposited at $10^{-2}$ mbar $\rightarrow$ CDC $3.2 \mu \mathrm{m}$ thick). In addition, the capacitance value delivered by the as-prepared on-chip CDC films was stable over 10000 cycles regardless of the TiC deposition pressure (Figure S6A, Supporting Information). The areal energy density is calculated as expressed in the Experimental Section. In terms of performance, the as-prepared TiC-CDC electrodes delivered high energy densities, moving from 6.0 to $11.6 \mu \mathrm{Wh} \mathrm{cm}{ }^{-2}$ while increasing the deposition pressure to produce stress-free and thick TiC layer. A Ragone plot is reported in Figure S6B (Supporting Information) in order to benchmark MSC based on CDC with other carbon technologies (graphene ${ }^{[37]}$ and carbon nanotubes ${ }^{[38]}$ ) tested in aqueous electrolytes. The fabrication process of such MSC has already been reported recently. ${ }^{[1]}$ For the sake of clarity, the energy and power densities are normalized to the footprint area, in an interdigitated electrode configuration. In this way, the areal energy density of a microsupercapacitor corresponds to capacitance of an electrode $\left(C_{\text {electrode }}\right)$ divided by $4\left(C_{\text {electrode }} / 2\right.$ in a parallel plate configuration). From this Figure S6B (Supporting Information), the performance of the CDC technology is clearly demonstrated, challenging the best carbon-based devices reported so far.

\section{Conclusion}

In summary, we have reported a fine-tuning of the sputtered TiC acting as a precursor metal carbide layer for CDC electrodes of micro-supercapacitors. Our strategy developed here allows us to produce thick, stress-free, and highly conductive TiC films. The ad-atoms diffusion process and atomic peening are crucial parameters to control the layer growth, which is, respectively, resulting from both the temperature and pressure parameters of the TiC sputtering process.

In this respect, the best compromise was achieved when the sputtering deposition of the TiC layers was performed at $750{ }^{\circ} \mathrm{C}$ and $10^{-2}$ mbar, allowing to produce the required metal carbide precursors for MSC electrodes. From electrochemical analyses, we show that the volumetric capacitance of three different TiC-CDC films deposited, respectively, at $10^{-3}, 5 \times 10^{-3}$, and $10^{-2}$ mbar, chlorinated at $450^{\circ} \mathrm{C}$ and tested in aqueous electrolyte is kept constant around $350 \mathrm{~F} \mathrm{~cm}^{-3}$. Nevertheless, to produce high surface capacitance, binder-free carbon electrodes, the thickness of the TiC-CDC layers should be raised. However, this raise is not reachable because the TiC thickness is limited by the high level of stress due to the low deposition pressure. The surface capacitance of the TiC-CDC electrodes shifts from 53 $\mathrm{mF} \mathrm{cm}{ }^{-2}$ for the TiC deposited at $10^{-3}$ mbar (CDC thickness = $1.5 \mu \mathrm{m})$ to $103 \mathrm{mF} \mathrm{cm}^{-2}$ for the sputtered TiC film at $10^{-2} \mathrm{mbar}$ (CDC thickness $=3.2 \mu \mathrm{m}$ ). We demonstrate here that the stress within the TiC deposited at $10^{-3} \mathrm{mbar}$ is so high that it results in cracks/delamination process of the layer as soon as the thickness of the TiC is higher than $2.5 \mu \mathrm{m}$. The mechanical integrity of the film and the adhesion on the silicon wafer is too weak for MSC application. The electrical conductivity value was estimated to be relatively high for both $\mathrm{TiC}$ and TiC-CDC layers on the condition that the deposition pressure is kept below $10^{-2}$ mbar. Definitively, this study on the sputtered TiC thick films paves the way to high surface capacitance electrodes for MSC applications.

\section{Experimental Section}

TiC Film Deposition: Titanium carbide (TiC) thin films were deposited using a nonreactive DC-MS on silicon $(\mathrm{Si})$ or $\mathrm{Si} / \mathrm{SiO}_{2}$ wafers. The (Alliance Concept) DP 650s sputtering equipment was used to achieve the thin film deposition after pumping to a base vacuum of $10^{-7} \mathrm{mbar}$. Homogeneous deposits were obtained by keeping the distance between the target and the substrate at $70 \mathrm{~mm}$. A TiC target $(99.5 \%, 10 \mathrm{~cm}$ diameter, $6 \mathrm{~mm}$ thick) was sputtered under argon atmosphere in the DP 650 sputtering equipment. DC power density, argon flow rate, deposition pressure, deposition time, and operating temperature during the deposition were investigated separately. The pressure in the chamber and the temperature (up to $750^{\circ} \mathrm{C}$ ) were carefully tuned for depositing highly conductive, dense, crystalline, stress free, thick, and smooth TiC thin films.

Electrical, Mechanical, and Structural Properties of the TiC Films: Electrical measurements (resistivity mapping) were achieved using a Semilab WT 2000PVN contactless equipment (mapping area $\# 3 \mathrm{~cm}^{2}$ ). Stress measurement was performed with the FSM 500 TC system using a nondestructive laser scanning technique to measure the change of curvature induced in the wafer due to the deposited film. A blank measurement was done on a 3 inch (100) silicon wafer (two perpendicular lines along the diameter are scanned). After the TiC deposit, a second scan was repeated; the film stress was deduced from the Stoney formula taking into account the two measured curvatures. An AFM (Dimension 3100) was used to measure the surface roughness of the TiC and CDC thin films. A Zeiss Ultra 55 SEM was used to determine the thickness of the TiC layers as well as their morphology.

Characterization of the $\mathrm{TiC}$ structure was performed using aberrationcorrected transmission electron microscope (JEOL-ARM200F). Highresolution TEM images and SAED patterns were acquired using this microscope at $200 \mathrm{keV}$ and equipped with a Cs image corrector and a Cold-FEG (field electron gun).

The samples were prepared by cutting thin slices of the $\mathrm{SiO}_{2} / \mathrm{TiC} / \mathrm{CDC}$ samples using FEI Strata DB 235 focused ion beam (FIB), perpendicularly to the surface. Raman spectra were recorded using a micro-Raman spectrometer LabRAM HR (Horiba Jobin-Yvon, wavelength $=473 \mathrm{~nm}$ ). The X-ray diffraction structural characterization of the films was undertaken using a Rigaku SMARTLAB multipurpose six-axis diffractometer ( $9 \mathrm{~kW}$ rotating anode) in Bragg-Brentano reflection or high resolution parallel beam modes (with soller slits $5^{\circ}$ and a PSD ID detector DTEX) delivering CuK $\alpha$ radiation $(\lambda=1.5418 \AA$ ). WDS (CAMECA SX 100) was used to determine the film composition and especially the $\mathrm{Ti} / \mathrm{C}$ ratio.

Chlorination of TiC Films Deposited Onto Si Wafers: All the TiC samples were transformed into porous $\mathrm{CDC}$ films by heat treatment at $450{ }^{\circ} \mathrm{C}$ under $\mathrm{Cl}_{2}$ atmosphere following the equation $\mathrm{TiC}+2 \mathrm{Cl}_{2} \rightarrow$ $\mathrm{TiCl}_{4}+\mathrm{C}$. Annealing was performed at $600{ }^{\circ} \mathrm{C}$ for $2 \mathrm{~h}$ under vacuum in order to remove the chlorine species trapped into the nanopores. The 
resulting nanoporous carbon was investigated as a CDC electrode for micro-supercapacitors.

Electrochemical Analysis of the CDC Electrodes: Electrochemical characterizations of the films were conducted using a multipotentiostat (VMP3, Biologic Company) in aqueous electrolyte $\left(1 \mathrm{M} \mathrm{H}_{2} \mathrm{SO}_{4}\right)$ using conventional three-electrode setup. The sample (CDC film grown from an underneath layer of $\mathrm{TiC}$ deposited onto $\mathrm{Si}$ wafer) was used as the working electrode. $\mathrm{A} \mathrm{Hg} / \mathrm{Hg}_{2} \mathrm{SO}_{4}$ electrode was used as reference, and a Pt plate was used as counter electrode. Contacts were achieved by pressing a stainless steel clip onto the carbon film. The areal energy densities were calculated from the following equation (Equation (3))

$E=\frac{1}{2} C V^{2}$

where $E$ stands for the areal energy density in $\mathrm{J} \mathrm{cm}^{-2}, C$ the capacitance in $\mathrm{F} \mathrm{cm}^{-2}$, and $V$ the potential window in volts. The energy density could be converted in $\mathrm{Wh} \mathrm{cm}^{-2}$ dividing by 3600 .

\section{Supporting Information}

Supporting Information is available from the Wiley Online Library or from the author.

\section{Acknowledgements}

M.L., L.B., and C.L. were supported by the French RENATECH network P.S., P.L.T., A.D., L.B., and C.L. thank the ANR (Labex Store-Ex and MINOTORES project) and the RS2E for their support. K.B. was supported by Chair of excellence from the Airbus Group. P.S. acknowledges the funding from the European Research Council (ERC Advanced Grant, "Ionaces" project). The authors thank the IS2M from Mulhouse for the use of the TEM. Authors thank A. Callewaert for helping to draw the first figure (structure zone model). The authors thank the Chevreul Federation for the funding.

[1] P. Huang, C. Lethien, S. Pinaud, K. Brousse, R. Laloo, V. Turq, M. Respaud, A. Demortiere, B. Daffos, P. L. Taberna, B. Chaudret, Y. Gogotsi, P. Simon, Science 2016, 351, 691.

[2] P. Simon, Y. Gogotsi, Nat. Mater. 2008, 7, 845.

[3] M. Toupin, T. Brousse, D. Bélanger, Chem. Mater. 2004, 16, 3184.

[4] E. Eustache, C. Douard, R. Retoux, C. Lethien, T. Brousse, Adv. Energy Mater. 2015, 5, 1.

[5] T. Brousse, D. Belanger, J. Electrochem. Soc. 2015, 162, 5185.

[6] J. Chmiola, Science 2006, 313, 1760.

[7] B. Hsia, J. Marschewski, S. Wang, J. Bin In, C. Carraro, D. Poulikakos, C. P. Grigoropoulos, R. Maboudian, Nanotechnology 2014, 25, 55401.
[8] D. Pech, M. Brunet, H. Durou, P. Huang, V. Mochalin, Y. Gogotsi, P.-L. Taberna, P. Simon, Nat. Nanotechnol. 2010, 5, 651.

[9] M. F. El-Kady, R. B. Kaner, Nat. Commun. 2013, 4, 1475.

[10] M. Heon, S. Lofland, J. Applegate, R. Nolte, E. Cortes, J. D. Hettinger, P. L. Taberna, P. Simon, P. H. Huang, M. Brunet, Y. Gogotsi, Energy Environ. Sci. 2011, 4, 135.

[11] Y. G. J. Chmiola, C. Largeot, P. L. Taberna, P. Simon, Science 2010, $328,480$.

[12] V. Presser, M. Heon, Y. Gogotsi, Adv. Funct. Mater. 2011, 21, 810.

[13] C. R. Perez, S. H. Yeon, J. Segalini, V. Presser, P. L. Taberna, P. Simon, Y. Gogotsi, Adv. Funct. Mater. 2013, 23, 1081.

[14] P. Huang, M. Heon, D. Pech, M. Brunet, P. L. Taberna, Y. Gogotsi, S. Lofland, J. D. Hettinger, P. Simon, J. Power Sources 2013, 225, 240.

[15] A. J. Detor, A. M. Hodge, E. Chason, Y. Wang, H. Xu, M. Conyers, A. Nikroo, A. Hamza, Acta Mater. 2009, 57, 2055.

[16] J. A. Thornton, Thin Solid Films 1989, 171, 5.

[17] A. Mani, P. Aubert, F. Mercier, H. Khodja, C. Berthier, P. Houdy, Surf. Coatings Technol. 2005, 194, 190.

[18] J.-E. Sundgren, B.-O. Johansson, S.-E. Karlsson, Thin Solid Films $1983,105,353$.

[19] J.-E. Sundgren, B.-O. Johansson, S.-E. Karlsson, H. T. G. Hentzell, Thin Solid Films 1983, 105, 367.

[20] H. T. G. Sundgren, J.-E. Johansson, B.-O. Karlsson, S.-E. Hentzell, Thin Solid Films 1983, 105, 385.

[21] M. Braic, N. C. Zoita, M. Danila, C. E. A. Grigorescu, C. Logofatu, Thin Solid Films 2015, 589, 590.

[22] N. C. Zoita, V. Braic, M. Danila, A. M. Vlaicu, C. Logofatu, C. E. A. Grigorescu, M. Braic, J. Cryst. Growth 2014, 389, 92.

[23] A. Z. Ait Djafer, N. Saoula, N. Madaoui, A. Zerizer, Appl. Surf. Sci. 2014, 312, 57

[24] Q. Qi, W. Z. Zhang, L. Q. Shi, W. Y. Zhang, W. Zhang, B. Zhang, Thin Solid Films 2012, 520, 6882

[25] J. A. Thornton, J. Vac. Sci. Technol. 1974, 11, 666.

[26] D. M. Devia, E. Restrepo-Parra, P. J. Arango, Appl. Surf. Sci. 2011, 258, 1164.

[27] E. Chason, B. W. Sheldon, L. B. Freund, J. A. Floro, S. J. Hearne, Phys. Rev. Lett. 2002, 88, 156103.

[28] P. R. Guduru, E. Chason, L. B. Freund, J. Mech. Phys. Solids 2003, $51,2127$.

[29] J. A. Thornton, Annu. Rev. Mater. Sci. 1977, 7, 239.

[30] J. A. Thornton, J. Vac. Sci. Technol., A 1986, 4, 3059.

[31] M. Andritschky, F. Guimardes, V. Teixeira, Vaccum 1993, 44, 809.

[32] P. B. Barna, M. Adamik, Thin Solid Films 1998, 317, 27.

[33] I. Petrov, P. B. Barna, L. Hultman, J. E. Greene, J. Vac. Sci. Technol., A 2003, 21, S117.

[34] S. Otani, T. Tanaka, Y. Ishizawa, J. Mater. Sci. 1986, 21, 1011.

[35] A. I. Gusev, Russ. Chem. Rev. 2002, 71, 439.

[36] F. Meng, S. A. Morin, A. Forticaux, S. Jin, Acc. Chem. Res. 2013, 46, 1616.

[37] M. F. El-Kady, V. Strong, S. Dubin, R. B. Kaner, Science 2012, 335, 1326.

[38] J. Lin, C. Zhang, Z. Yan, Y. Zhu, Z. Peng, R. H. Hauge, D. Natelson, J. M. Tour, Nano Lett. 2013, 13, 72. 